\title{
Intake of dietary iron is low in patients with Crohn's disease: a case-control study
}

\author{
Miranda C. E. Lomer ${ }^{1 *}$, Kamelia Kodjabashia ${ }^{1}$, Carol Hutchinson², Simon M. Greenfield ${ }^{3}$, \\ Richard P. H. Thompson ${ }^{1}$ and Jonathan J. Powell ${ }^{2}$ \\ 'Gastrointestinal Laboratory, The Rayne Institute, St Thomas' Hospital, Lambeth Palace Road, London SE1 7EH, \\ UK \\ ${ }^{2}$ Department of Nutrition and Dietetics, Franklin-Wilkins Building, King's College London, 150 Stamford Street, \\ London SE1 9NN, UK \\ ${ }^{3}$ Department of Gastroenterology, Queen Elizabeth II Hospital, Howlands, Welwyn Garden City, \\ Hertfordshire AL7 4HQ, UK
}

(Received 13 May 2003 - Revised 18 August 2003 - Accepted 10 September 2003)

\begin{abstract}
Patients with Crohn's disease (CD) often experience Fe deficiency (ID) and frequently alter their diet to relieve abdominal symptoms. The present study set out to assess whether patients with $\mathrm{CD}$ have dietary habits that lead to low $\mathrm{Fe}$ intakes and/or reduced bioavailable Fe compared with control subjects. Patients with asymptomatic CD were matched to controls ( $n$ 91/group). Dietary intakes of Fe and contributions from different food groups were compared using a $7 \mathrm{~d}$ food diary. Promoters and inhibitors of non-haem Fe absorption were investigated and a recently published algorithm was applied to assess bioavailable Fe. Fewer patients than controls met the reference nutrient intake for Fe (32\% CD patients $v .42 \%$ controls). Overall, patients had significantly lower mean Fe intakes (by $2.3 \mathrm{mg} / \mathrm{d}$ ) and Fe density (by $0.26 \mathrm{mg} / \mathrm{MJ}(1.1 \mathrm{mg} / 1000 \mathrm{kcal})$ ) compared with controls (both $P<0.001)$. Differences were mainly due to a preference among $\mathrm{CD}$ patients for low-fibre non-Fe fortified cereals, particularly breakfast cereals. In particular, control subjects had higher Fe intakes than matched CD subjects for men $(P<0.001)$ and women less than 50 years $(P=0.03)$. Intakes of both ascorbic acid $(P<0.001)$ and phytic acid $(P<0 \cdot 01)$, but not animal tissue $(P=1 \cdot 0)$, were lower in patients with $\mathrm{CD}$, but these had no overall effect on the predicted percentage of bioavailable Fe. Thus total bioavailable Fe was reduced in patients with CD due to lower intakes $(P<0 \cdot 01)$. Dietary Fe intakes are low in CD patients, which may contribute to an increased risk of ID and anaemia. Changing dietary advice may compromise perceived symptoms of the disease so the need for Fe supplementation should be carefully considered.
\end{abstract}

Iron intake: Diet: Iron deficiency: Crohn's disease

Crohn's disease (CD) is an inflammatory bowel disease characterised by patchy, transmural inflammation of mainly the ileum and colon. Although formal prospective studies do not exist it is generally accepted that $\mathrm{Fe}$ deficiency (ID) is common in CD (Gasche et al. 1994, 1997; Harvey et al. 1998; Mamula et al. 2002; Erichsen et al. 2003). This is based upon (a) frequent clinical observations; (b) retrospective analysis and audit of patient notes (Child et al. 1973; Thomson et al. 1978; Gasche et al. 1994; De Silva et al. 2001a,b; Oldenburg et al. 2001); (c) response to oral or intravenous Fe therapy (Gasche et al. 1997, 2001; Harvey et al. 1998). The latter point is important as anaemia of chronic disease can be difficult to separate from ID but, in a series of carefully controlled studies, Gasche et al. $(1997,2001)$ have demonstrated that about $75 \%$ of patients with anaemia and CD respond to Fe therapy leading also to a significant improvement in their quality of life. Reasons for ID in CD are not completely clear but, being an inflammatory bowel disease, loss of blood and protein in the gastrointestinal tract is one obvious risk and increased mucosal Fe levels seem probable in inflammatory bowel disease (Millar et al. 2000; Erichsen et al. 2003). However, unlike with coeliac disease, $\mathrm{Fe}$ malabsorption is unlikely to occur in CD since Fe absorption occurs proximally while the disease predominates distally. Indeed, limited studies have suggested that Fe absorption is unaltered in patients with CD (Bartels et al. 1978). However, sub-optimal dietary $\mathrm{Fe}$ intake has not been widely considered as a potential contributor to ID in CD, and yet deserves attention because food aversions and self-reported food intolerance are common in this patient group (Ballegaard et al. 1997; Mishkin, 1997). Thus patients often alter their diet to reduce abdominal symptoms, such as pain and diarrhoea (Ballegaard et al. 1997).

A number of studies have evaluated dietary Fe intake in inflammatory bowel disease (Hodges et al. 1984; Gee et al. 
1985a,b; Imes et al. 1987; Geerling et al. 1998), but have generally involved small numbers, lacked appropriate control groups and often had insufficient specificity or selectivity to estimate Fe intakes with any confidence.

Dietary Fe occurs in two forms, namely haem and nonhaem. In an omnivorous diet, approximately $10 \%$ of total dietary $\mathrm{Fe}$ is haem $\mathrm{Fe}$, which is obtained from meat, poultry and fish (Monsen et al. 1978). The remaining $90 \%$ of dietary $\mathrm{Fe}$ is non-haem and mainly obtained from plant sources. The absorption of haem and non-haem Fe ranges from 15 to $35 \%$ and 2 to $20 \%$ respectively, depending on many factors, including the presence of dietary promoters and inhibitors for non-haem $\mathrm{Fe}$ absorption (Morris, 1987; Monsen, 1988; Hunt, 1996).

The present study investigated whether dietary Fe intake is lower in patients with CD compared with controls. Since the total amount of $\mathrm{Fe}$ in the diet is a poor indicator of bioavailable (absorbable) Fe (Monsen et al. 1978; Tseng et al. 1997; Hallberg \& Hulthen 2000; Reddy et al. 2000), a recently described $\mathrm{Fe}$ absorption algorithm (Reddy et al. 2000) was also used to estimate the amount of dietary $\mathrm{Fe}$ that was potentially bioavailable in the two groups.

\section{Materials and methods}

\section{Study design}

Patients with CD (aged 23-65 years; $n$ 91) were recruited from gastrointestinal outpatient clinic records at $\mathrm{St}$ Thomas' Hospital (London), Queen Elizabeth II Hospital (Welwyn Garden City, Hertfordshire) and The Lister Hospital (Stevenage, Hertfordshire). Control subjects (aged 23-66 years; $n$ 91) were recruited from general practitioner (GP) clinics local to the hospitals; namely, Lambeth Walk Group Practice (London) and Bridge Cottage Surgery (Welwyn Garden City, Hertfordshire). The CD patients and controls were matched for age ( \pm 5 years), sex, ethnicity, area of residence and social class. The present study size would detect a significant difference of $3.0 \mathrm{mg} / \mathrm{d}$ in total $\mathrm{Fe}$ intake, assuming a standard deviation in each group of $6.0 \mathrm{mg}$ (Hodges et al. 1984; Gee et al. 1985b; Department of Health, 1991) with $80 \%$ power at the $5 \%$ significance level. Local ethics committees for Guy's and St Thomas' NHS Trust and the East and North Hertfordshire NHS Trust approved the study, and all subjects were invited to take part over the course of 1 year (September 1999 to August 2000).

\section{Subjects}

Prospective cases (aged $19-68$ years; $n$ 302) and controls (aged 18-70 years; $n$ 547) were initially contacted by post either by their consultant gastroenterologist (cases) or their GP (controls). Those willing to participate returned a pre-paid reply card to the investigators for potential recruitment into the study.

\section{Cases}

Patients with CD were invited by their consultant gastroenterologist to respond to the investigators if they were in self-reported disease remission (median 12 months). Upon recruitment to the study, symptoms needed to be absent for at least 1 week. However, the interval since each patient's last relapse was recorded, because disease severity and activity can influence appetite (Geerling et al. 1998; Riordan et al. 1998). Three patients with CD were taking prescribed oral Fe medication (ferrous sulfate) and, as for controls, neither this nor self-prescribed supplements were included in the results for dietary $\mathrm{Fe}$ intakes. This was to ensure that intakes reflected only nutrients coming from the diet and not from supplements.

\section{Controls}

Individuals were chosen at random by administrative staff from GP records held on a database and then those without diagnosed gastrointestinal or other chronic disease were contacted by their GP. Controls who replied to the invitation provided a brief medical history to confirm the absence of gastrointestinal or chronic disease and were matched to the responding patients with $\mathrm{CD}(1: 1)$ for age ( \pm 5 years), sex, ethnicity, social class and area of residence. All recruited subjects were allocated to a social class according to the criteria of the Registrar General's scale (Reid, 1980). Although the groups were not matched for BMI there were no significant differences between cases $\left(23 \cdot 3(\mathrm{SD} 4 \cdot 3) \mathrm{kg} / \mathrm{m}^{2}\right)$ and controls (24.1 (SD 3.7) $\mathrm{kg} / \mathrm{m}^{2}$ ) (paired Student's $t$ test; $P=0 \cdot 2$ ).

\section{Dietary assessment}

Following recruitment and informed consent, all subjects were taught to complete a validated $7 \mathrm{~d}$ food diary (Bingham et al. 1997). Seasonal differences in food choice were restricted by ensuring that the matched cases and controls were selected at the same time of year, although seasonal variations in food supply in industrial societies are small (Bingham, 1987).

Each interview lasted approximately $30 \mathrm{~min}$ and the subjects were shown how to complete the food diary, using their previous day's dietary intake as an example. This indicates the detail required and helps to eliminate any bias in the subject's response (Bingham et al. 1997). The subjects were requested to record food items at the time of eating to minimise reliance on memory (Buzzard, 1998), thus limiting recall error and reducing the risk of omitting dietary items or misinterpreting portion sizes.

The food diary contained full instructions, examples of descriptions of meals and seventeen sets of photographs with three portion choices for each food. Photographs improve estimates of portion size (Faggiano et al. 1992; Nelson et al. 1996), and so the subjects were taught how to use the portion-size photographs as a guide for other similar foods. Where appropriate, the subjects were also allowed to state portion sizes in convenient household measurements or pack sizes if they preferred. Instructions were given to clearly describe recipes, cooking methods, and the type and brand name of food and drink consumed.

The participants were asked to fill in the remaining $6 \mathrm{~d}$ of the diary maintaining their usual eating habits and to return the completed diary in a pre-paid envelope. In addition, the 
subjects were asked to answer a number of general questions regarding their dietary intake, such as the type of milk (whole, semi-skimmed or skimmed) most frequently used during the recording period. The questions served as a crosscheck and were intended to confirm the accuracy of the account (Bingham, 1987).

Subjects who failed to return their diary $7 \mathrm{~d}$ after the expected date of completion were contacted by telephone and, if necessary, a second telephone reminder was given 1 week later.

\section{Nutrient database}

Energy and nutrient intakes were generated using a nutrient analysis database program (Lomer, 2002) and the food composition tables for the UK (Holland et al. 1991). The database was updated with published values for phytic acid (Harland \& Oberleas, 1987) and estimated amounts of animal tissue (Monsen \& Balintfy, 1982), which are two factors in the Fe absorption algorithm (Reddy et al. 2000). For quality control, food records were screened for errors before analysis. Data were crosschecked for input errors, such as duplicate entries and values outside the expected range for weight of portion size $(\mathrm{g})$, energy $(\mathrm{kJ})$ and a few selected nutrients (Lomer, 2002).

\section{Data analysis}

Comparisons were made between the patients with CD and the controls using the paired Student's $t$ test for continuous data and the $\chi^{2}$ test for categorical data. In all tests significance was assumed where $P \leq 0.05$ and results are expressed as mean values and standard deviations. Where multiple comparisons are presented of independent data the $P$ values are adjusted according to the Bonferroni method for limited multiple comparisons (i.e. $P$ value $X$ number of comparisons) and the treatment of data is given in the footnotes to each Table. Analyses were carried out for energy, protein, fat, carbohydrate, Fe intake and $\mathrm{Fe}$ density (i.e. $\mathrm{mg} / \mathrm{MJ}$ and $\mathrm{mg} / 1000 \mathrm{kcal}$ ). Fe intakes were compared with the dietary reference values and according to different $\mathrm{Fe}$ requirements (Department of Health, 1991). Hence, the cases and controls were subdivided to investigate $\mathrm{Fe}$ intakes in male subjects, and in females under and over 50 years of age, which is a commonly used arbitrary cut-off for menopausal status. As noted earlier, analyses were also carried out to calculate the contribution of different food groups to Fe intake and to assess potentially bioavailable haem and non-haem $\mathrm{Fe}$ in the cases and controls. Potentially bioavailable dietary haem Fe was assumed to be $25 \%$ in all subjects, based on studies in healthy volunteers consuming mixed meals (Monsen et al. 1978; Hunt \& Roughead, 2000). Recently two Fe absorption algorithms have been published (Hallberg \& Hulthen, 2000; Reddy et al. 2000) that take into account the combined effect of enhancers and inhibitors of nonhaem Fe absorption in mixed meals. In the present study an adapted algorithm of Reddy et al. (2000) was used since this is easily applied and involves only three major dietary factors affecting Fe bioavailability (ascorbic acid, phytic acid and animal tissue). Hence:
Ln potentially bioavailable $\mathrm{Fe}(\%)=\mathrm{Ln}$ Fe absorption adjusted for serum ferritin concentration of $30 \mu \mathrm{g} / \mathrm{l}$ $(\%)=1.9786+(0.0123 \times$ animal tissue per $\mathrm{d} / 3(\mathrm{~g}))-$ $(0.0034 \times$ phytic acid per $\mathrm{d} / 3(\mathrm{mg}))+(0.0065 \times$ ascorbic acid per $\mathrm{d} / 3(\mathrm{mg}))$.

In the originally described algorithm (Reddy et al. 2000), absorption of dietary $\mathrm{Fe}$ is determined by the $\mathrm{Fe}$ quantity and quality and by the individual's capacity for Fe absorption. The latter is estimated from plasma ferritin levels, but in chronic disease, such as $\mathrm{CD}$, this may be misleading as ferritin can be elevated independently of $\mathrm{Fe}$ status. In any case, the present study aimed to identify dietary $\mathrm{Fe}$ intake in $\mathrm{CD}$ patients rather than its absorption and so, without reference to serum ferritin levels, potentially bioavailable $\mathrm{Fe}$ rather than $\mathrm{Fe}$ absorption was estimated as shown in the equation shown earlier. Dietary factors (weight/d) are each divided by 3 as the original algorithm is based upon individual meals rather than daily intakes.

\section{Results}

Subjects

Overall, 302 cases were invited and 114 replied. Of these, 102 matched the recruitment criteria but then two never returned diaries and nine others could not be matched to controls. Controls continued to be recruited until matching to the ninety-one cases was achieved. Invitations were sent to 547 controls; 126 replied and 110 were recruited. Six of these did not return diaries and thirteen could not be matched.

\section{Iron intake}

Mean energy, protein, fat and carbohydrate intakes were not significantly different between the patients with $C D$ and controls, whereas mean Fe intake was significantly lower in the patients by $2.3 \mathrm{mg} / \mathrm{d}(P<0.001)$, as was mean $\mathrm{Fe}$ density by $0.26 \mathrm{mg} / \mathrm{MJ} \quad(1.1 \mathrm{mg} / 1000 \mathrm{kcal})$ $(P<0.001$; Table 1). Thus fewer patients with CD compared with the controls met the reference nutrient intake (RNI) (Department of Health, 1991) for Fe (32\% CD patients v. $42 \%$ controls; Figs. 1 and 2). All subgroups of patients with $\mathrm{CD}$ had, on average, lower mean Fe intakes than the controls, but this only reached significance for males $(P<0.001)$ and females 50 years of age or under $(P=0.03$; Fig. 1$)$. In the CD patients, there was no obvious association between $\mathrm{Fe}$ intakes and interval since the last disease relapse (Pearson's correlation $r 0.1 ; P=0.2$ ) and there was no significant difference in Fe intake between the patients with or without disease relapse in the previous 12 months $(P=0 \cdot 9)$.

\section{Food groups}

Cereals, meat and vegetables contributed 80 and $76 \%$ of the dietary $\mathrm{Fe}$ for the cases and controls, respectively. However, cereals contributed $1.7 \mathrm{mg}$ less dietary $\mathrm{Fe}$ in the cases than in controls $(P<0 \cdot 001$; Table 2$)$, accounting for the majority of the difference between the groups. On further analysis, the mean Fe intake from bread and 
Table 1. Nutrient intakes in Crohn's disease (cases) and controls*

(Mean values, standard deviations and ranges)

\begin{tabular}{|c|c|c|c|c|c|c|c|}
\hline & \multicolumn{3}{|c|}{ Controls ( $n$ 91) } & \multicolumn{3}{|c|}{ Cases ( $n 91)$} & \multirow[b]{2}{*}{$P+$} \\
\hline & Mean & SD & Range & Mean & SD & Range & \\
\hline Energy: MJ/d & $8 \cdot 795$ & $2 \cdot 13$ & $3 \cdot 427-14 \cdot 175$ & $8 \cdot 707$ & $2 \cdot 19$ & $4.025-14.422$ & \\
\hline $\mathrm{kcal} / \mathrm{d}$ & 2102 & 509 & $819-3388$ & 2081 & 523 & $962-3447$ & 1.0 \\
\hline Protein (mg/d) & $79 \cdot 2$ & $19 \cdot 8$ & $25-131$ & 74.4 & $19 \cdot 2$ & $37-116$ & 0.5 \\
\hline Fat $(g / d)$ & $81 \cdot 0$ & 24.5 & $21 \cdot 6-152 \cdot 4$ & $86 \cdot 0$ & $27 \cdot 8$ & $17 \cdot 5-169 \cdot 9$ & 1.0 \\
\hline Carbohydrate $(\mathrm{g} / \mathrm{d})$ & 238 & $61 \cdot 2$ & $57 \cdot 1-370 \cdot 0$ & 242 & $68 \cdot 2$ & $100-410$ & 1.0 \\
\hline $\mathrm{Fe}(\mathrm{mg} / \mathrm{d})$ & $11 \cdot 6$ & $4 \cdot 2$ & $5 \cdot 1-27 \cdot 5$ & $9 \cdot 3$ & $3 \cdot 2$ & $3 \cdot 3-20 \cdot 6$ & $<0.001$ \\
\hline $\mathrm{Fe}$ density: $\mathrm{mg} / \mathrm{MJ}$ & 1.34 & 0.45 & $0.74-3.18$ & 1.08 & 0.26 & $0.48-2.06$ & \\
\hline $\mathrm{mg} / 1000 \mathrm{kcal}$ & $5 \cdot 6$ & 1.9 & $3 \cdot 1-13 \cdot 3$ & 4.5 & $1 \cdot 1$ & $2 \cdot 0-8 \cdot 6$ & $<0.001$ \\
\hline
\end{tabular}

${ }^{*}$ For details of subjects and procedures, see pp. $142-143$.

† $P$ values are presented as the original $P$ value $\times 5$ (since five independent comparisons were made) and are shown as 1.0 for all results $\geq 1 \cdot 0$.

breakfast cereals was less in the cases than controls, differing by $0.3 \mathrm{mg} / \mathrm{d}(P=0 \cdot 04)$ and $1.5 \mathrm{mg} / \mathrm{d} \quad(P<0.001)$, respectively (Table 2 ).

\section{Potentially bioavailable haem and non-haem iron}

The mean intake of haem $\mathrm{Fe}$ and, therefore, its potential bioavailability were similar for the controls and patients with $\mathrm{CD}$ and represented less than $10 \%$ of total $\mathrm{Fe}$ intake and approximately $15 \%$ of potentially bioavailable Fe (Table 3).

The mean intake of non-haem Fe was $2.4 \mathrm{mg} / \mathrm{d}$ lower in the patients with $\mathrm{CD}$ than in the controls $(P<0 \cdot 001)$. Compared with the controls, the patients with $\mathrm{CD}$ had significantly lower mean intakes of ascorbic acid $(P<0.001)$, predominantly due to the consumption of less fruit, and lower mean intakes of phytic acid $(P<0 \cdot 01)$, whereas consumption of animal tissue (meat, poultry and fish) was similar for both groups $(P=1 \cdot 0$; Table 3$)$. These three factors were used in the algorithm for assessing non-haem $\mathrm{Fe}$ bioavailability (see p. 143) and similar percentages were observed in the two groups $(10.6 \%$ patients and $10.7 \%$ controls, $P=0.9$; Table 3 ). Thus, the total dietary $\mathrm{Fe}$

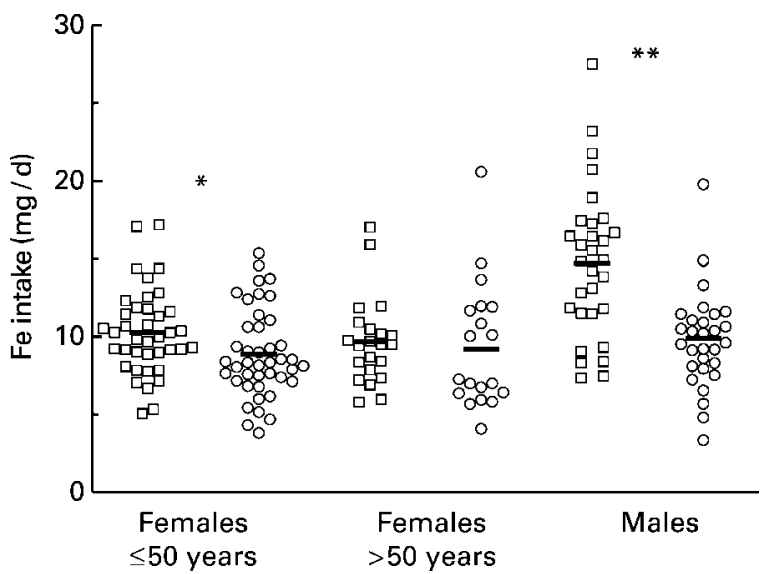

Fig. 1. Mean daily $\mathrm{Fe}$ intakes of male and female Crohn's disease cases ( $($ ) and controls ( $\square$ ) aged 50 years or under and over 50 years of age. Mean value (-) for the Crohn's disease cases was significantly lower than for the controls: * $P=0.03$, ${ }^{\star *} P<0.001$.
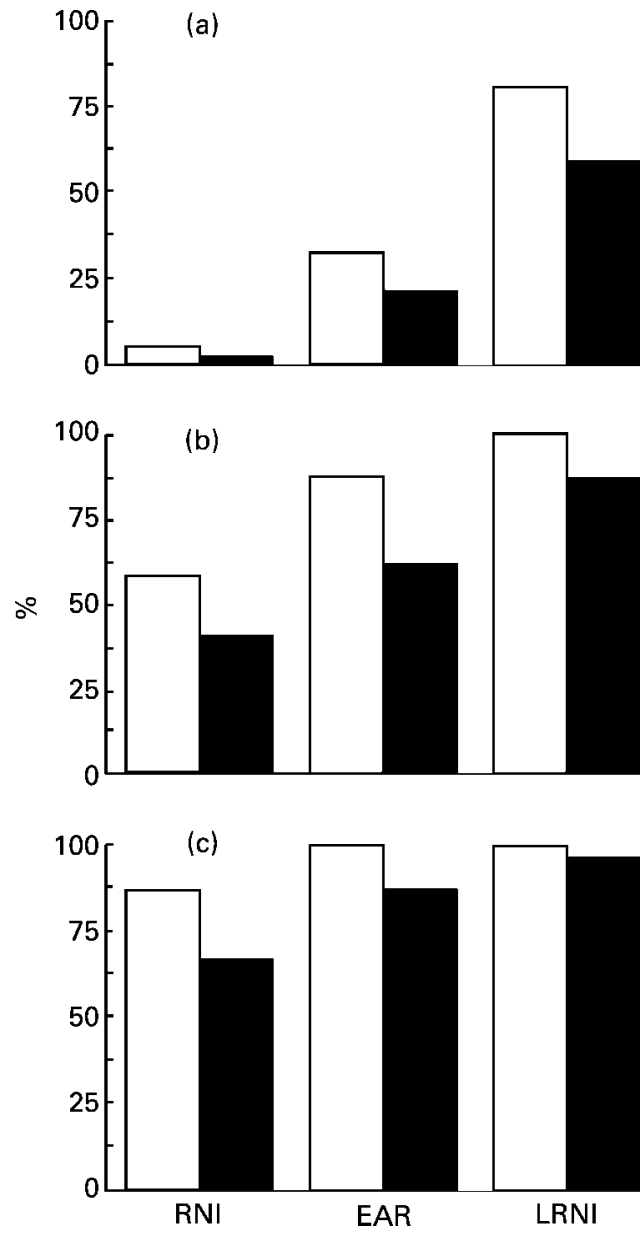

Fig. 2. The percentages of Crohn's disease cases ( $\square$ ) and controls $(\square)$ who met the dietary reference values for Fe (Department of Health, 1991) for (a) females aged 50 years or under, (b) females aged over 50 years and (c) males. Reference nutrient intakes (RNI) for $\mathrm{Fe}$ are $14.8 \mathrm{mg} / \mathrm{d}$ (females aged 50 years or under), and $8.7 \mathrm{mg} / \mathrm{d}$ (males, and females aged over 50 years). Estimated average requirements (EAR) for $\mathrm{Fe}$ are $11.4 \mathrm{mg} / \mathrm{d}$ (females aged 50 years or under), and $6.7 \mathrm{mg} / \mathrm{d}$ (males, and females aged over 50 years). Lower reference nutrient intakes (LRNI) for Fe are $8.0 \mathrm{mg} / \mathrm{d}$ (females aged 50 years or under), and $4.7 \mathrm{mg} / \mathrm{d}$ (males, and females aged over 50 years). 
Table 2. Iron intake from the top contributing food groups in patients with Crohn's disease (cases) and controls*

(Mean values and standard deviations)

\begin{tabular}{|c|c|c|c|c|c|}
\hline & \multicolumn{4}{|c|}{ Fe intake $(\mathrm{mg} / \mathrm{d})$} & \multirow[b]{3}{*}{$P \dagger$} \\
\hline & \multicolumn{2}{|c|}{ Controls } & \multicolumn{2}{|c|}{ Cases } & \\
\hline & Mean & SD & Mean & SD & \\
\hline Cereals & $5 \cdot 6$ & 3.6 & 3.9 & $2 \cdot 0$ & $<0.001$ \\
\hline Bread $\ddagger$ & $2 \cdot 4$ & $1 \cdot 0$ & $2 \cdot 1$ & $1 \cdot 2$ & 0.04 \\
\hline Breakfast cereals $\ddagger$ & 2.4 & 3.4 & 0.9 & $1 \cdot 2$ & $<0.001$ \\
\hline Meat & 1.6 & 1.0 & 1.9 & 1.4 & 0.1 \\
\hline Vegetables & 1.6 & 0.8 & 1.6 & 1.0 & 0.9 \\
\hline
\end{tabular}

*For details of subjects and procedures, see pp. 142-143.

† These outcomes represent subgroup analysis from a previously established difference in Fe intake (see Fig. 1) so $P$ values have not been presented with Bonferroni correction.

$\ddagger$ Selected food subgroups.

(haem and non-haem) that was potentially bioavailable was still $17 \%$ lower in the cases than in the controls $(P<0 \cdot 01$; Table 3$)$.

\section{Discussion}

Anaemia in patients with $\mathrm{CD}$ may be a consequence of inflammation (anaemia of chronic disease); however ID also occurs frequently and is estimated to occur in about $30 \%$ of patients at any one time (Gasche et al. 1994; Oldenburg et al. 2001). Reasons for this are not completely clear although abnormal Fe loss in the gastrointestinal tract is probable. However, the present study also suggests that significantly reduced non-haem Fe intake occurs in patients with $\mathrm{CD}$ probably as a result of avoidance of certain Fe-rich and fortified foods. Typically these are 'fibrous' in nature and may be avoided by patients for fear of exacerbating symptoms. The present study now shows that, overall, this results in an intake of about $20 \%$ less dietary $\mathrm{Fe}$ than in a carefully matched control population.

Previous studies have suggested insignificant differences in $\mathrm{Fe}$ intakes between $\mathrm{CD}$ patients and controls, but have been underpowered (Geerling et al. 1998) and/or lacking control groups (Hodges et al. 1984; Imes et al. 1987). Moreover these previous studies generally assessed $\mathrm{Fe}$ intake as one of many variables and/or used food-frequency questionnaires. The former further reduces power while the latter is only semi-quantitative, often overestimating absolute nutrient intakes and requiring large numbers of subjects for best usage (Bingham, 1987). Indeed, in former studies, energy and $\mathrm{Fe}$ intakes were higher than in the present investigation and were surprisingly high compared with expected national averages (Hodges et al. 1984; Imes et al. 1987; Geerling et al. 1998). The present study used a $7 \mathrm{~d}$ food diary, which compares well with $16 \mathrm{~d}$ weighed records for the correct ranking of subjects and has been validated in the UK population (Bingham et al. 1997) although mild to moderate under-reporting can still occur. Overall, energy intakes may have been marginally low in the present study (about $8.8 \mathrm{MJ}(2100 \mathrm{kcal}) / \mathrm{d})$ but neither this nor BMI varied between the groups suggesting that observations between the groups remain valid.

The male control subjects consumed $14.7 \mathrm{mg} \mathrm{Fe} / \mathrm{d}$, which is in close agreement with British dietary survey data (Gregory et al. 1990). However, both groups of female control subjects had low Fe intakes compared with the British survey data with females aged 50 years or under consuming the least compared with their RNI. This group has a high requirement for dietary $\mathrm{Fe}$ due to the extra Fe losses during menstruation, but often fail to meet the RNI of $14.8 \mathrm{mg} / \mathrm{d}$ in the UK (Department of Health, 1991) or the RDA of $15 \mathrm{mg} / \mathrm{d}$ in the USA (National Research Council, 1989). Most notably, however, the matched subjects with CD (females aged 50 years or

Table 3. Potentially bioavailable haem and non-haem iron intakes in Crohn's disease (cases) and controls* (Mean values and standard deviations)

\begin{tabular}{|c|c|c|c|c|c|}
\hline & \multicolumn{2}{|c|}{ Controls } & \multicolumn{2}{|c|}{ Cases } & \multirow[b]{2}{*}{$P+$} \\
\hline & Mean & SD & Mean & SD & \\
\hline Haem Fe $(\mathrm{mg} / \mathrm{d}) \ddagger$ & 0.78 & 0.49 & 0.90 & 0.59 & $0 \cdot 2$ \\
\hline Potentially bioavailable haem $\mathrm{Fe}(\mathrm{mg} / \mathrm{d}) \S$ & 0.19 & 0.12 & 0.22 & $0 \cdot 15$ & 0.2 \\
\hline Non-haem Fe $(\mathrm{mg} / \mathrm{d})$ & $10 \cdot 8$ & $4 \cdot 1$ & 8.4 & 3.0 & $<0.001$ \\
\hline Animal tissue $(\mathrm{g} / \mathrm{d}) \ddagger$ & 97 & 50 & 93 & 43 & 1.0 \\
\hline Ascorbic acid (mg/d) & 118 & 63 & 80 & 54 & $<0.001$ \\
\hline Phytic acid (mg/d) & 285 & 239 & 176 & 169 & $<0.01$ \\
\hline Bioavailability of non-haem Fe (\%)\| & $10 \cdot 7$ & 3.6 & $10 \cdot 6$ & 2.48 & 0.9 \\
\hline Potentially bioavailable non-haem Fe (mg/d) & $1 \cdot 14$ & 0.55 & 0.89 & 0.37 & $<0.001$ \\
\hline Total potentially bioavailable $\mathrm{Fe}(\mathrm{mg} / \mathrm{d})$ & $1 \cdot 34$ & 0.61 & $1 \cdot 11$ & 0.46 & $<0.01$ \\
\hline
\end{tabular}

${ }^{*}$ For details of subjects and procedures, see pp. 142-143.

†Fe-related outcomes represent subgroup analysis from a previously established difference in Fe intake (see Fig. 1) so, in these cases, $P$ values have not been presented with Bonferroni correction. For animal tissue, ascorbic acid and phytic acid, $P$ values are presented as the original $P$ value $\times 3$ (since three independent comparisons were made) and are shown as 1.0 for results $\geq 1.0$.

¥The trend towards a higher intake of animal tissue but a lower intake of haem Fe in controls compared with cases is explained by group preferences for red meat (tending to be higher in cases) or poultry and fish (tending to be higher in controls).

§ Based upon $25 \%$ bioavailability (Monsen et al. 1978; Harland \& Oberleas, 1987; see p. 143)

$\|$ Adapted from the equation of Reddy et al. (2000; see p. 143). 
under) had even lower Fe intakes and yet probably have greater dietary Fe requirements due to protein and blood losses during active disease (Oldenburg et al. 2001). Female patients of 50 years or under make up a large proportion of patients with $\mathrm{CD}$ since, presently, it is an increasingly prevalent disease, with a slight female bias (Lashner, 1995) that tends to affect younger individuals (National Association for Colitis and Crohn's Disease, 2002). Overall it is striking that the Fe intakes in the present study not only failed to reach the RNI in many patients, but also were even lower than the $\mathrm{Fe}$ intakes in a matched control population. These findings suggest that one of the reasons for the suggested high prevalence of ID in patients with $\mathrm{CD}$ is sub-optimal $\mathrm{Fe}$ intake.

In the present study, all patients with $\mathrm{CD}$ had been in remission for at least 1 week, which, for some, would be a relatively short period of time (19\% for 1-4 weeks) although the median was 12 months. Intakes of Fe could have been altered in patients who had recently experienced a period of increased disease activity, since it is recognised that energy intakes are significantly reduced in active CD (Thomas et al. 1993; Rigaud et al. 1994) but not during periods of disease remission (Thomas et al. 1993). However, mean energy and macronutrient intakes were not significantly different in the patients and controls. Moreover, there was no association between Fe intakes and time since the last relapse of disease or between those with recent relapses $(<1$ year) $v$. those with longer-term remission $(>1$ year). Taken together, these data suggest that reduced dietary Fe intake in patients with $\mathrm{CD}$ was due to the habitual consumption of foods containing less $\mathrm{Fe}$, and not due to reduced food or $\mathrm{Fe}$ intake in response to disease activity.

Cereals, meat and vegetables provide $80 \% \mathrm{Fe}$ in the British diet (Gregory et al. 1990). In the present study meat provided around $10 \%$ dietary $\mathrm{Fe}$ intake. Although haem $\mathrm{Fe}$ is of relatively high bioavailability, meat is not generally a high source of the total dietary Fe intake in the UK (typically $<15 \%$; Lynch, 2002). This is in spite of the fact that there were only three vegetarians in the control group and one in the CD group and that red meat was not consumed by only five controls and four cases. A similar contribution to dietary Fe came from vegetables, mostly potatoes, peas, green beans, broccoli and baked beans. However, cereal-based foods, due to fortification, were by far the greatest contributor to dietary $\mathrm{Fe}$ as noted elsewhere in the UK (Gibson, 1999). The bioavailability of $\mathrm{Fe}$ in fortified cereals is influenced by dietary components such as phytic acid and ascorbic acid (Gibson, 1999) but most Fe-fortified breakfast cereals, which are naturally high in phytic acid, are not fortified with ascorbic acid.

Patients with $\mathrm{CD}$ often avoid specific foods, even in inactive disease, due to the fear of precipitating abdominal symptoms. Indeed, intolerance of cereals, fibrous fruits and vegetables is commonly reported (Ballegaard et al. 1997). Hence, in the present study, potential differences in dietary habits leading to lower $\mathrm{Fe}$ intakes in cases were investigated. As noted earlier, the patients with $\mathrm{CD}$ consumed significantly less $\mathrm{Fe}$ from cereals, especially breakfast cereals. High-fibre breakfast cereals are fortified with more Fe compared with lowfibre breakfast cereals (Holland et al. 1991), and it appears that the cases consumed less Fe from breakfast cereals due to a preference for low-fibre cereals.

An estimate of the bioavailability of non-haem Fe in the two groups, by applying the equation of Reddy et al. (2000), did not change the overall picture of reduced dietary Fe exposure in $\mathrm{CD}$ patients. There was no overall influence of the effects of a low intake of ascorbic acid (promoter) and a low intake of phytic acid (inhibitor) in the patients with CD. However, decreased intakes of these nutrients is in agreement with the findings of past studies (Martini \& Brandes, 1976; Thomas et al. 1993; Ballegaard et al. 1997; Russel et al. 1998), in which patients with CD consumed significantly less fruit and vegetables and wholegrain foods compared with controls. Presumably, therefore, on this occasion, the effects of a lowphytic-acid diet counteracted the effects of a lowascorbic-acid diet when considering overall Fe bioavailability although the limits of such predictive algorithms should be recognised. Absolute bioavailability must be difficult to predict accurately, and clearly varies with each meal and subject factor (Lynch, 2002), so it should only be concluded that there was no obvious compensatory factor in the diet of cases to increase their Fe bioavailability $v$. that of controls.

In conclusion, reduced dietary Fe intake, largely due to the avoidance of certain cereals, and in particular breakfast cereals, may contribute to ID in CD patients. In patients with $\mathrm{CD}$, the reduced intake of ascorbic acid and phytic acid has no overall effect on the potential availability of dietary non-haem Fe. However, changing dietary advice for CD patients may prove unsuccessful, as patients may resist altering their diet for fear of exacerbating abdominal symptoms. Hence, careful dietary Fe supplementation for patients with $\mathrm{CD}$ should be especially considered.

\section{Acknowledgements}

The authors thank Dr Jeremy Sanderson and Dr John Meenan at Guy's and St Thomas' NHS Trust, London, Dr Adrian Catterall, at the Lister Hospital, Stevenage, Hertfordshire and Dr Peter McIntyre at Queen Elizabeth II Hospital, Welwyn Garden City, Hertfordshire for access to their CD patient databases. The authors also thank Professor Roger Jones at Lambeth Group Practice, London and Dr Roger Aubrey at Bridge Cottage Surgery, Welwyn Garden City, Hertfordshire for inviting their patients to take part as controls. Finally the authors thank Sara Volkert for help with data collection and computer entry. M. C. E. L. was a research training fellow funded by the NHS Executive London Regional Office. The authors are grateful to SynerMed for support.

\section{References}

Ballegaard M, Bjergstrom A, Brondum S, Hylander E, Jensen L \& Ladefoged K (1997) Self-reported food intolerance in chronic inflammatory bowel disease. Scand J Gastroenterol 32, 569-571. 
Bartels U, Pedersen NS \& Jarnum S (1978) Iron absorption and serum ferritin in chronic inflammatory bowel disease. Scand $J$ Gastroenterol 13, 649-656.

Bingham SA (1987) The dietary assessment of individuals; methods, accuracy, new techniques and recommendations. Nutr Abstr Rev 57A, 705-742.

Bingham SA, Gill C, Welch A, et al. (1997) Validation of dietary assessment methods in the UK arm of EPIC using weighed records, and 24-hour urinary nitrogen and potassium and serum vitamin $\mathrm{C}$ and carotenoids as biomarkers. Int J Epidemiol 26, S137-S151.

Buzzard M (1998) 24-hour dietary recall and food record methods. In Nutritional Epidemiology, pp. 50-73 [WC Willett, editor]. New York: Oxford University Press.

Child JA, Brozovic B, Dyer NH, Mollin DL \& Dawson AM (1973) The diagnosis of iron deficiency in patients with Crohn's disease. Gut 14, 642-648.

Department of Health (1991) Dietary Reference Values for Food Energy and Nutrients for the United Kingdom. Report on Health and Social Subjects no. 41. London: H.M. Stationery Office.

De Silva AD, Mylonaki M \& Rampton DS (2001a) Efficacy and usage of oral iron therapy in inflammatory bowel disease. Gastroenterology 120, 1393S.

De Silva AD, Mylonaki M \& Rampton DS (2001b) Prevalence of usage and tolerance of oral iron therapy in inflammatory bowel disease: are we using it appropriately and could we do better? Gut 48, 333S.

Erichsen K, Hausken T, Ulvik RJ, Svardal A, Berstad A \& Berge RK (2003) Ferrous fumerate deteriorated plasma antioxidant status in patients with Crohn disease. Scand J Gastroenterol 38, 543-548.

Faggiano F, Vineis P, Cravanzola D, et al. (1992) Validation of a method for the estimation of food portion size. Epidemiology $\mathbf{3}$, 379-382.

Gasche C, Dejaco C, Waldhoer T, et al. (1997) Intravenous iron and erythropoietin for anemia associated with Crohn disease. A randomized, controlled trial. Ann Intern Med 126, 782-787.

Gasche C, Reinisch W, Lochs H, et al. (1994) Anemia in Crohn's disease. Importance of inadequate erythropoietin production and iron deficiency. Dig Dis Sci 39, 1930-1934.

Gasche C, Waldhoer T, Feichtenschlager T, et al. (2001) Prediction of response to iron sucrose in inflammatory bowel diseaseassociated anemia. Am J Gastroenterol 96, 2382-2387.

Gee MI, Grace MG, Wensel RH, Sherbaniuk R \& Thomson AB (1985a) Protein-energy malnutrition in gastroenterology outpatients: increased risk in Crohn's disease. $J$ Am Diet Assoc 85 , $1466-1474$

Gee MI, Grace MG, Wensel RH, Sherbaniuk RW \& Thomson AB (1985b) Nutritional status of gastroenterology outpatients: comparison of inflammatory bowel disease with functional disorders. J Am Diet Assoc 85, 1591-1599.

Geerling BJ, Badart-Smook A, Stockbrugger RW \& Brummer RJ (1998) Comprehensive nutritional status in patients with longstanding Crohn disease currently in remission. Am J Clin Nutr 67, 919-926.

Gibson SA (1999) Iron intake and iron status of preschool children: associations with breakfast cereals, vitamin $\mathrm{C}$ and meat Public Health Nutr 2, 521-528.

Gregory J, Foster K, Tyler H \& Wiseman M (1990) Dietary and Nutritional Survey of British Adults. London: HM Stationery Office.

Hallberg L \& Hulthen L (2000) Prediction of dietary iron absorption: an algorithm for calculating absorption and bioavailability of dietary iron. Am J Clin Nutr 71, 1147-1160.

Harland BF \& Oberleas D (1987) Phytate in foods. World Rev Nutr Diet 52, 235-259.
Harvey RS, Reffitt DM, Doig LA, et al. (1998) Ferric trimaltol corrects iron deficiency anaemia in patients intolerant of iron. Aliment Pharmacol Ther 12, 845-848.

Hodges P, Gee M, Grace M \& Thomson AB (1984) Vitamin and iron intake in patients with Crohn's disease. J Am Diet Assoc 84, $52-58$.

Holland B, Welch AA, Unwin ID, Buss DH, Paul AA \& Southgate DAT (1991) McCance and Widdowson's The Composition of Foods. London: The Royal Society of Chemistry.

Hunt JR (1996) Bioavailability algorithms in setting recommended dietary allowances: lessons from iron, applications to zinc. $J$ Nutr 126, 2345S-2353S.

Hunt JR \& Roughead ZK (2000) Adaptation of iron absorption in men consuming diets with high or low iron bioavailability. Am J Clin Nutr 71, 94-102.

Imes S, Pinchbeck BR \& Thomson AB (1987) Diet counseling modifies nutrient intake of patients with Crohn's disease. $J$ Am Diet Assoc 87, 457-462.

Lashner BA (1995) Epidemiology of inflammatory bowel disease. Gastroenterol Clin North Am 24, 467-474.

Lomer MCE (2002) Dietary microparticles and Crohn's disease, $\mathrm{PhD}$ thesis: University of London.

Lynch S (2002) Food iron absorption and its importance for the design of food fortification strategies. Nutr Rev 60, S3-S6.

Mamula P, Piccoli DA, Peck SN, Markowitz JE \& Baldassano RN (2002) Total dose intravenous infusion of iron dextran for iron-deficiency anaemia in children with inflammatory bowel disease. J Pediatr Gastroenterol Nutr 34, 286-290.

Martini GA \& Brandes JW (1976) Increased consumption of refined carbohydrates in patients with Crohn's disease. Klin Wochenschr 54, 367-371.

Millar AD, Rampton DS \& Blake DR (2000) Effects of iron and iron chelation in vitro on mucosal oxidant activity in ulcerative colitis. Aliment Pharmacol Ther 14, 1163-1168.

Mishkin S (1997) Dairy sensitivity, lactose malabsorption, and elimination diets in inflammatory bowel disease. Am J Clin Nutr 65, 564-567.

Monsen ER (1988) Iron nutrition and absorption: dietary factors which impact iron bioavailability. J Am Diet Assoc 88, 786-790.

Monsen ER \& Balintfy JL (1982) Calculating dietary iron bioavailability: refinement and computerization. J Am Diet Assoc 80, 307-311.

Monsen ER, Hallberg L, Layrisse M, et al. (1978) Estimation of available dietary iron. Am J Clin Nutr 31, 134-141.

Morris ER (1987) Iron. In Trace Elements in Human and Animal Nutrition, pp. 79-142 [W Mertz, editor]. New York: Academic Press.

National Association for Colitis and Crohn's Disease (2002) Statement on age distribution of Crohn's disease. http:/www. nacc.org.uk.

National Research Council (1989) Recommended Dietary Allowances. Washington, DC: National Academy Press.

Nelson M, Atkinson M \& Darbyshire S (1996) Food photography II: use of food photographs for estimating portion size and the nutrient content of meals. Br J Nutr 76, 31-49.

Oldenburg B, Koningsberger JC, Berge Henegouwen GP, Van Asbeck BS \& Marx JJ (2001) Iron and inflammatory bowel disease. Aliment Pharmacol Ther 15, 429-438.

Reddy MB, Hurrell RF \& Cook JD (2000) Estimation of nonheme-iron bioavailability from meal composition. Am J Clin Nutr 71, 937-943.

Reid I (1980) Social class, ethnicity, sex, and age in empirical research. In Social Class Differences in Britain; Life-chances \& Lifestyles. London: Fontana Press.

Rigaud D, Angel LA, Cerf M, et al. (1994) Mechanisms of decreased food intake during weight loss in adult Crohn's 
disease patients without obvious malabsorption. Am J Clin Nutr 60, 775-781.

Riordan AM, Ruxton CH \& Hunter JO (1998) A review of associations between Crohn's disease and consumption of sugars. Eur J Clin Nutr 52, 229-238.

Russel MG, Engels LG, Muris JW, et al. (1998) 'Modern life' in the epidemiology of inflammatory bowel disease: a casecontrol study with special emphasis on nutritional factors. Eur J Gastroenterol Hepatol 10, 243-249.

Thomas AG, Taylor F \& Miller V (1993) Dietary intake and nutritional treatment in childhood Crohn's disease. J Parenteral Enteral Nutr 17, 75-81.

Thomson AB, Brust R, Ali MA, Mant MJ \& Valberg LS (1978) Iron deficiency in inflammatory bowel disease. Diagnostic efficacy of serum ferritin. Am J Dig Dis 23, 705-709.

Tseng M, Chakraborty H, Robinson DT, Mendez M \& Kohlmeier L (1997) Adjustment of iron intake for dietary enhancers and inhibitors in population studies: bioavailable iron in rural and urban residing Russian women and children. J Nutr 127, 1456-1468. 